\title{
Effect of Hydrogen Sulphide Contamination on Platinum Catalyst Degradation in Polymer Electrolyte Membrane Fuel Cells
}

\author{
A. Dushina, P. Wagner, and A. Dyck \\ DLR Institute of Networked Energy Systems, Carl-von-Ossietzky-Str. 15, 26129 \\ Oldenburg, Germany
}

\begin{abstract}
The effect of $\mathrm{H}_{2} \mathrm{~S}$ contamination on platinum catalyst in PEMFC has been investigated in terms of rotation disk electrode measurements in $0.1 \mathrm{M} \mathrm{HClO}_{4}$. The electrochemical surface area was determined by hydrogen underpotential deposition and $\mathrm{CO}$ stripping method before and after accelerated stress tests (AST). The observed losses of ECSA of the catalyst in the presence of $\mathrm{H}_{2} \mathrm{~S}$ were associated to the adsorbed sulphur on the catalyst surface which changed cyclic voltammetric characteristics of the material. The RDE experiments revealed that ORR mass and specific activities were essentially decreased after AST with $\mathrm{H}_{2} \mathrm{~S}$ contaminations attributed to the interstitial defect on platinum atom sites due to the adsorbed sulphur. The HR-TEM has not revealed any significant differences between the catalyst surface morphology before and after test while EDX mapping indicated higher amount of the sulphur after AST confirming the presence of adsorbed sulphur species on the platinum catalyst surface.
\end{abstract}

\section{Introduction}

Polymer electrolyte membrane fuel cells (PEMFC) are highly promising energy conversion units with low environmental impact, high theoretical efficiency and zero $\mathrm{CO}_{2}$ emissions (1-2). In PEMFC carbon supported platinum nanoparticles are usually used as electrocatalyst material regarding their high active surface area and reactivity for oxygen reduction reaction being the most important cathodic reaction in PEMFC (3-4). Over the last two decades, they have been extensively studied and developed with the aim of widespread commercialization. However, this technology still faces many limitations and one of them is the presence of impurities in the fuel stream which prevent hydrogen oxidation reaction leading to the performance degradation and sometimes damage of the membrane electrode assembly (MEA). The most studied contaminations in the hydrogen fuel are carbon monoxide, carbon dioxide, hydrogen sulphide and ammonia. The U.S. Department of energy (DOE) requests the following level of impurities in fuel: $2 \mu \mathrm{mol}$ $\mathrm{mol}^{-1}$ of $\mathrm{CO}_{2}, 0.2 \mu \mathrm{mol} \mathrm{mol}{ }^{-1}$ of $\mathrm{CO}, 0.004 \mu \mathrm{mol} \mathrm{mol}^{-1}$ of sulphur species, and $0.1 \mu \mathrm{mol}$ $\mathrm{mol}^{-1}$ of $\mathrm{NH}_{4}(5)$.

Sulphur components, such as $\mathrm{H}_{2} \mathrm{~S}$, have a direct and dramatic influence on platinum catalyst in PEMFC. Even though, this contaminant, usually present in a very low concentration in fuel stream, is a strong poison for fuel cell catalysts. 
In an early study Loučka reported that kinetics of $\mathrm{H}_{2} \mathrm{~S}$ adsorption and oxidation on $\mathrm{Pt}$ electrodes depends on dehydrogenation of $\mathrm{H}_{2} \mathrm{~S}$ and thus formed hydrogen was oxidized at positive electrode potentials (6). Sethuraman et al. found that the poisoning effect of the $\mathrm{H}_{2} \mathrm{~S}$ is cumulative and irreversible while no recovery of the cell performance appeared after exposure to pure $\mathrm{H}_{2}$ (7). Mohtadi was studying the recovery of membrane electrode assemblies after exposure to $\mathrm{H}_{2} \mathrm{~S}$ and demonstrated that the degree of the recovery is influenced by the electrochemical oxidation of two surface species observed during cyclic voltammetry experiments (8). Further they investigated the relationship between the Pt coverage with sulphur and the $\mathrm{H}_{2} \mathrm{~S}$ dosage at different temperatures. It was found that sulphur adsorbs more strongly at lower cell operating temperatures (9). Nagahara et al. demonstrated that PEMFC performance loss is attributed to decrease of available Pt sites for oxygen reduction reaction (ORR) (10).

However, to the best of our knowledge the kinetic aspects of the degradation of platinum electrocatalyst in the presence of $\mathrm{H}_{2} \mathrm{~S}$ have not been yet investigated adequately. Therefore, in this work the influence of $\mathrm{H}_{2} \mathrm{~S}$ contamination on commercially available $\mathrm{Pt}$ catalyst with carbon support was studied by means of rotating disk electrode experiments in perchloric acid. Accelerated stress testing (AST) was performed in terms of potential cycling up to 10,000 cycles in the absence of contaminants and in the presence of $\mathrm{H}_{2} \mathrm{~S}$ for comparison. Cyclic voltammetry technique in terms of hydrogen under potential deposition (HUPD) and CO stripping was employed in order to determine the electrochemical surface area (ECSA). Oxygen reduction reaction (ORR) was used to identify kinetic parameters including kinetic limited current, Tafel slopes, mass and specific activity of the catalyst before and after AST.

\section{Experimental}

All the electrochemical experiments were performed using the bipotentiostat PGSTAT132N (Metrohm Autolab, The Netherlands) controlled by Nova 1.11 software connected to the three-electrode electrochemical cell. Rotating disk electrodes (RDE) comprising glassy carbon $\left(\mathrm{A}=0.196 \mathrm{~cm}^{2}\right)$ with Teflon ${ }^{\circledR}$ jacket and fixed inside a rotation system (Pine Research Instrumentation, USA) - were employed as working electrode (WE). Platinum wire was used as the counter electrode (CE) while a mercury/mercury sulphate reference electrode (RE) was used, and all potential values were reported against the reversible hydrogen electrode, RHE.

Measurements were carried out in $0.1 \mathrm{M} \mathrm{HClO}_{4}$ electrolyte (70 wt\%, Sigma-Aldrich, USA) at room temperature. Before use, the WE was polished with 1.00 and $0.05 \mu \mathrm{m}$ alumina paste (Buehler, USA) to a mirror finish and then sonicated in 2-propanol and in water for $10 \mathrm{~min}$.

The RDE was prepared by depositing Pt catalyst ink according to the following procedure: $1 \mathrm{mg}$ of Pt on carbon support catalyst powder was weighed in a glass vial; 0.6 $\mathrm{mL}$ of millipore water, $0.4 \mathrm{~mL}$ of isopropanol and $1.5 \mu \mathrm{L}$ of perfluorosulfonic acid-based ionomer solution were added to the weighed catalyst powder and the mixture was ultrasonicated for $20 \mathrm{~min}$. To achieve a platinum loading of $20 \mu \mathrm{g} \mathrm{cm}{ }^{-2}, 6.9 \mu \mathrm{L}$ of catalyst ink was dropped on the RDE and dried under rotation with $300 \mathrm{rpm}$. 
Before electrochemical characterisation of material the activation of the Pt catalyst in terms of surface cleaning and particles arrangement on the carbon surface was done by cyclic voltammetry in the potential range $0.05-1.05 \mathrm{~V}$ vs RHE at $150 \mathrm{mV} \mathrm{s}^{-1}$ within 100 cycles. Then, the catalyst was initially characterized by two methods, HUPD and CO stripping, in order to determine electrochemical surface area (ECSA). For both techniques the potential range $0.05-1.05 \mathrm{~V}$ vs RHE was chosen at scan rate $100 \mathrm{mV} \mathrm{s}^{-1}$ and $50 \mathrm{mV} \mathrm{s}^{-1}$, respectively, up to 3 cycles.

To study ORR kinetics, CV curves were performed in the potential range $0.05-1.15$ $\mathrm{V}$ vs RHE at $10 \mathrm{mV} \mathrm{s}^{-1}$ and 3 cycles at $400 \mathrm{rpm}$ in $\mathrm{O}_{2}$-saturated electrolyte. The rotation rate $400 \mathrm{rpm}$ was chosen due to the fact that higher rotation speed may accelerate the loss of contaminant into the electrolyte that prevents an expected poisoning effect of $\mathrm{H}_{2} \mathrm{~S}(6)$.

After initial characterization, the catalyst was aged by use of accelerated stress testing (AST) in the absence and in the presence of $1 \mathrm{ppm}_{2} \mathrm{~S}$ gas in the potential range $0.05-$ $1.05 \mathrm{~V}$ vs RHE at $500 \mathrm{mV} \mathrm{s}^{-1}$ up to 10,000 cycles. After that, ECSA and ORR experiments were repeated in order to determine the changes after AST in the absence and presence of the $\mathrm{H}_{2} \mathrm{~S}$.

The high resolution transmission electron microscopy (HR-TEM) JEM2100F (JEOL USA Inc., USA) combined with energy-dispersive X-ray spectroscopy (EDX) system INCA Energy TEM250 (Oxford Instruments plc, UK) with X-Max80 SDD-Detector were additionally used to image catalyst morphology changes after AST. For this aim a gold grid with 400 meshes (H7, Plano GmbH, Germany) was prepared by putting a drop of catalyst-water-suspension on the grid. The dried grid was fixed onto the working electrode of glassy carbon and then connected to the electrochemical setup. Finally, the platinum catalyst could be imaged before and after AST.

\section{Results and Discussion}

First, the AST of the catalyst was done in terms of the cyclic voltammetry in $0.1 \mathrm{M}$ $\mathrm{HClO}_{4}$ at a scan rate $500 \mathrm{mV} \mathrm{s}^{-1}$ for 10,000 cycles. As a reference a clean non-poisoned platinum catalyst was tested for comparison. Figure 1 shows typical cyclic voltammetry response obtained for reference and $\mathrm{H}_{2} \mathrm{~S}$-poisoned samples in the first, the middle and the last cycles of the test.
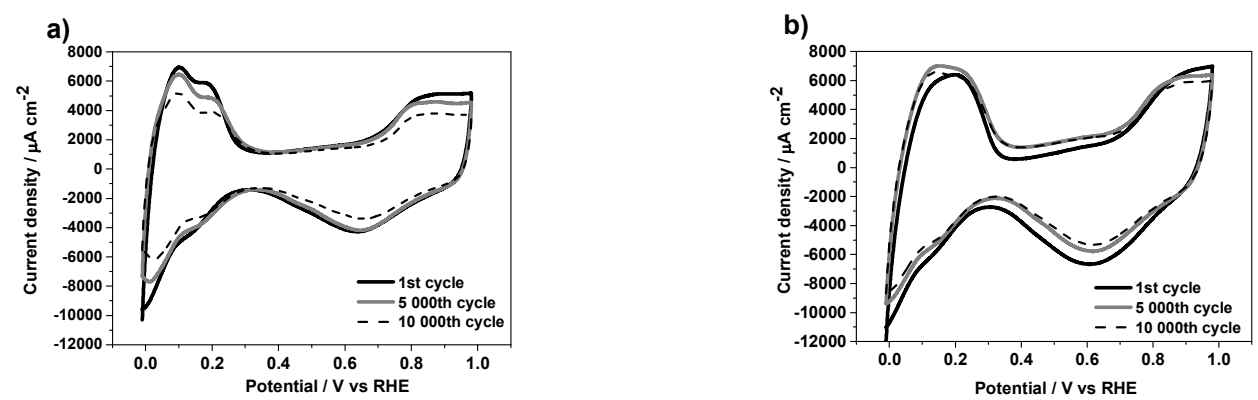

Figure 1. Cyclic voltammogram of the reference (a) and $\mathrm{H}_{2} \mathrm{~S}$-poisoned (b) platinum catalyst in $0.1 \mathrm{M} \mathrm{HClO}_{4}$ in the potential range $0.05-1.05 \mathrm{~V}$ vs RHE at $500 \mathrm{mV} \mathrm{s}^{-1}$. 
Both samples present the typical behaviour associated with hydrogen desorption/adsorption $(0.05-0.4 \mathrm{~V})$ and oxidation/reduction of platinum $(0.7-0.9 \mathrm{~V})$ peaks. However, it can be seen that during AST on the $\mathrm{H}_{2} \mathrm{~S}$-poisoned catalyst two peaks in the potential range $0.05-0.3 \mathrm{~V}$ are poorly defined, in comparison to the reference catalyst. The double layer capacitance region between $0.3-0.5 \mathrm{~V}$ after AST as well as the peak for the platinum oxidation in the potential range $0.7-0.9 \mathrm{~V}$ of the poisoned catalyst is significantly higher. Moreover, the oxygen evolution reaction of reference is hindered while for the $\mathrm{H}_{2} \mathrm{~S}$-poisoned sample it is clear visible at the potential around 1.0 $\mathrm{V}$ vs RHE. For the reference sample the current density is increasing with the cycling while for the poisoned catalyst the current density is first increasing and then slightly decreasing. It can be clearly seen that the presence of the $\mathrm{H}_{2} \mathrm{~S}$ modifies the cyclic voltammetric characteristics of the Pt-nanoparticles that can be related to the adsorbed sulphur on the Pt surface. Similar results were obtained in the work of Garsany, where the impact of $\mathrm{SO}_{2}$ on the kinetics of platinum-based catalysts was studied. It was shown that after the exposure of platinum catalyst to $1 \mathrm{ppm} \mathrm{SO}_{2}$ the reduction peak at $0.1 \mathrm{~V}$ within the hydrogen region was less pronounced in the presence of sulphur poisoning species (11).

Figure 2 shows cyclic voltammetry curves of the platinum catalyst before and after AST in $0.1 \mathrm{M} \mathrm{HClO}_{4}$ in the potential range $0.05-1.05 \mathrm{~V}$ vs RHE at $100 \mathrm{mV} \mathrm{s}^{-1}$. It can be seen that the peak of the hydrogen adsorption on $\mathrm{Pt}$ in the potential range $0.05-0.23$ $\mathrm{V}$ has decreased after corrosion for both samples. Similar decreasing of current can be observed for the platinum oxidation peak in the potential range at $0.8-0.85 \mathrm{~V}$ related to the less active sites of catalyst. Furthermore, the ECSA was determined by hydrogen underpotential deposition (HUPD) method which considers the oxidation charge of adsorbed hydrogen on platinum $\left(Q_{H}\right)$ in the potential range $0.0-0.4 \mathrm{~V}$ vs RHE according to Eq. [1]:

$$
E C S A_{H 2}=\frac{Q_{H}}{v \cdot \rho \cdot L_{P t}}
$$

where $v$ is scan rate, $\rho$ is a charge density $\left(2.1 \mathrm{C} \mathrm{m}_{\mathrm{Pt}}^{-2}\right)$ and $L_{P t}$ is a Pt loading $\left(30 \mu \mathrm{g} \mathrm{cm}^{-2}\right)(12)$.

a)

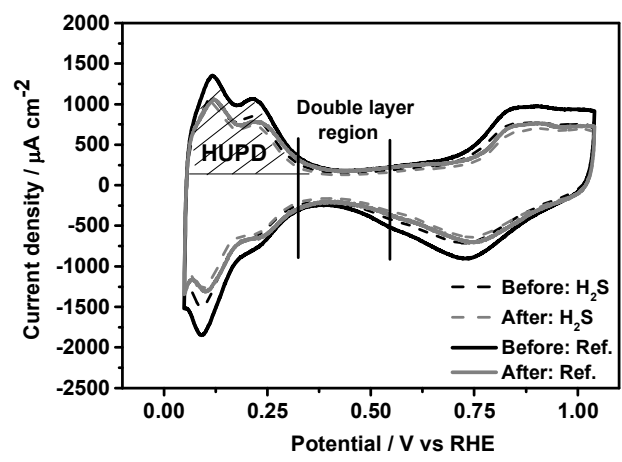

b)

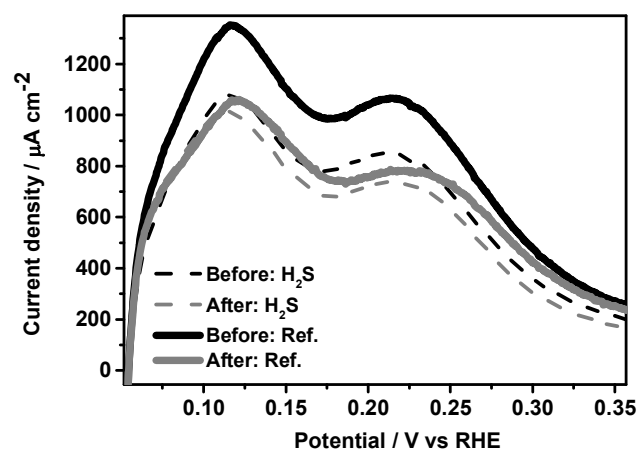

Figure 2. (a) Cyclic voltammetry for the reference and $\mathrm{H}_{2} \mathrm{~S}$-poisoned Pt catalyst for the HUPD method (b) Enlargement of the HUPD peaks of platinum before and after AST in $0.1 \mathrm{M} \mathrm{HClO}_{4}$ in the potential range $0.05-1.05 \mathrm{~V}$ vs RHE at $100 \mathrm{mV} \mathrm{s}^{-1}$. 
The second method used to calculate ECSA was CO-stripping method which takes into account adsorption and then oxidation of carbon monoxide on platinum in the potential range $0.6-0.8 \mathrm{~V}$ vs RHE. ECSA can be calculated according to Eq. [2]:

$$
E C S A_{C O}=\frac{Q_{C O}}{v \cdot \rho \cdot L_{P t}}
$$

where $Q_{C O}$ is oxidation charge of $\mathrm{CO}$ on platinum, $v$ is scan rate, $\rho$ is a charge density $\left(4.2 \mathrm{C} \mathrm{m}_{\mathrm{Pt}}{ }^{-2}\right)$ and $L_{P t}$ is a Pt loading $\left(30 \mu \mathrm{g} \mathrm{cm}^{-2}\right)(12)$.

Figure 3 illustrates $\mathrm{CO}$ stripping voltammograms for reference and $\mathrm{H}_{2} \mathrm{~S}$-poisoned catalysts for a full sweep from 0.05 to $1.05 \mathrm{~V}$ in $0.1 \mathrm{M} \mathrm{HClO}_{4}$. The strong anodic $\mathrm{CO}$ peak at around $0.69 \mathrm{~V}$ was observed for both samples before AST. After AST for reference sample a potential shift of about $+5 \mathrm{mV}$ occurs where for $\mathrm{H}_{2} \mathrm{~S}$-poisoned catalyst the shift $-8 \mathrm{mV}$ appears. The negative shift of potential indicates an easier $\mathrm{CO}$ electrooxidation and an improved CO tolerance by sulphide adsorption (11).

a)

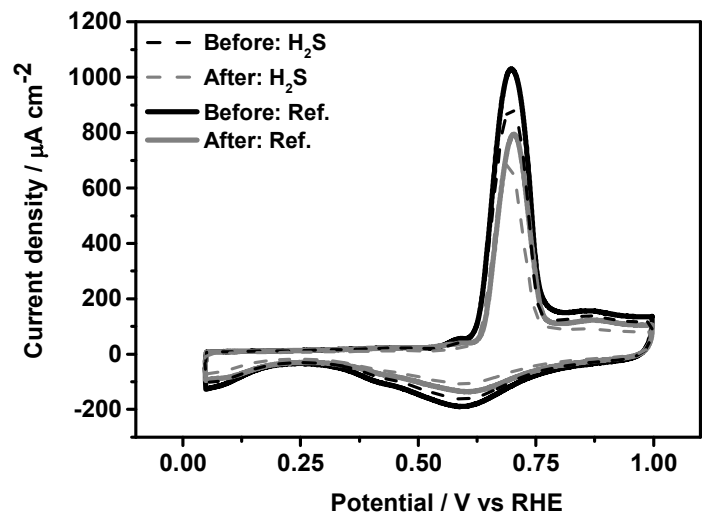

b)

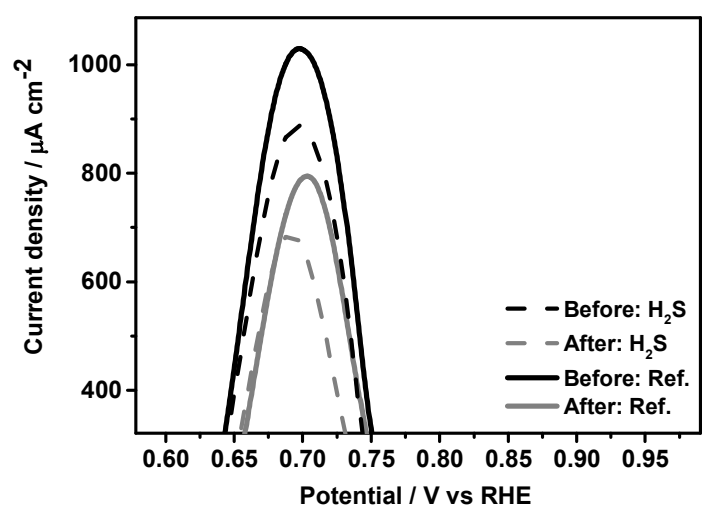

Figure 3. (a) CO stripping voltammogram of the Pt catalyst and (b) Enlargement of the $\mathrm{CO}$ peaks of platinum before and after AST in $0.1 \mathrm{M} \mathrm{HClO}_{4}$ in the potential range $0.05-$ $1.05 \mathrm{~V}$ vs RHE at $50 \mathrm{mV} \mathrm{s}^{-1}$.

Table I summarized the results for the calculated ECSA by HUPD and CO stripping methods. For reference sample the calculated ECSA of the catalyst determined by HUPD method was equal to $55 \pm 2$ and $43 \pm 2 \mathrm{~m}^{2} \mathrm{~g}^{-1}$ before and after AST, respectively, with $21 \%$ loss. In the presence of $\mathrm{H}_{2} \mathrm{~S}$ it was equal to $46 \pm 2$ and $37 \pm 2 \mathrm{~m}^{2} \mathrm{~g}^{-1}$ before and after AST, respectively, with $19 \%$ losses. The obtained ECSA of catalyst determined by CO stripping method for the reference sample was equal to $62 \pm 3$ and $43 \pm 3 \mathrm{~m}^{2} \mathrm{~g}^{-1}$ before and after AST, respectively, with $30 \%$ loss. For the $\mathrm{H}_{2} \mathrm{~S}$-poisoned catalyst $22 \%$ losses were determined while the ECSA decreased from $54 \pm 3$ to $42 \pm 3 \mathrm{~m}^{2} \mathrm{~g}^{-1}$ due to AST. 
TABLE I. ECSA of Platinum Catalyst Before and After AST for Reference and $\mathrm{H}_{2} \mathrm{~S}$-Poisoned Samples Derived by HUPD and CO Stripping Methods.

\begin{tabular}{ccccccc}
\hline \multirow{2}{*}{$\mathbf{E C S A}, \mathbf{~ m}^{\mathbf{2}} \mathbf{g}_{\mathbf{P t}}{ }^{-1}$} & \multicolumn{3}{c}{ Reference Sample } & \multicolumn{2}{c}{$\mathbf{H}_{\mathbf{2}} \mathbf{S}-$ Poisoned Sample } \\
\cline { 2 - 7 } & Before & After & Loss, $\%$ & Before & After & Loss, $\%$ \\
\hline HUPD & $55 \pm 2$ & $43 \pm 2$ & 21 & $46 \pm 2$ & $37 \pm 2$ & 19 \\
CO & $62 \pm 3$ & $43 \pm 3$ & 30 & $54 \pm 3$ & $42 \pm 3$ & 22 \\
\hline
\end{tabular}

Both methods reveal that ECSA of the $\mathrm{H}_{2} \mathrm{~S}$-poisoned sample is lower in comparison to the reference catalyst. Before AST during $\mathrm{H}_{2} \mathrm{~S}$ purging into the electrolyte sulphur adsorbed on the surface of platinum leading to its lower ECSA in comparison to the nonpoisoned catalyst.

The small difference in ECSA values obtained by HUPD and CO stripping methods may be explained through the fact that the electrochemical surface area is affected by many reasons including platinum particle sizes and their distribution on the substrate, electrical conductivity, surface area and functional surface groups of the support. Moreover, in HUPD method it is assumed that a monolayer of one hydrogen atom is bonded to one platinum atom, while in the case of $\mathrm{CO}$ stripping two platinum atoms are involved in the process (13-14).

Therefore, both methods are in a good agreement to each other with the average value for ECSA of the reference sample 58.5 and $43 \mathrm{~m}^{2} \mathrm{~g}^{-1}$ before and after AST, respectively. For the $\mathrm{H}_{2} \mathrm{~S}$-poisoned sample the values are equal to 50 and $39.5 \mathrm{~m}^{2} \mathrm{~g}^{-1}$ before and after AST, respectively.

It was reported in literature that adsorption of sulphur on platinum in diluted aqueous solution results in water soluble sulphate anion formation in accordance to the Eq. [3] proposed by Loučka (6):

$$
\mathrm{Pt}-\mathrm{S}_{\mathrm{ad}}+4 \mathrm{H}_{2} \mathrm{O} \rightarrow \mathrm{SO}_{4}{ }^{2-}+8 \mathrm{H}^{+}+6 \mathrm{e}^{-}+\mathrm{Pt}
$$

The platinum surface covered by sulphur (surface coverage, $\theta_{\mathrm{S}}$ ) was estimated from the amount of charge consumed in the hydrogen desorption defined here as a ratio of the sulphur oxidation charge, $\mathrm{Q}_{\mathrm{S}}$, to the charge for hydrogen oxidation, $\mathrm{Q}_{\mathrm{H}}$, which correlates to the platinum surface area in accordance to the Eq. [4]:

$$
\theta_{\mathrm{S}}=\mathrm{Q}_{\mathrm{S}} / 6 \mathrm{Q}_{\mathrm{H}}
$$

where $Q_{S}$ was determined by subtracting the anodic charge for the cathodic one in the potential range $0.05-1.05 \mathrm{~V}$ so that the hydrogen desorption/adsorption and oxygen oxidation/ reduction peaks fully cancel each other (11).

The values for $\theta_{\mathrm{S}}$ were calculated for the $1^{\text {st }}, 5,000^{\text {th }}$ and $10,000^{\text {th }}$ cycles of the AST and were equal to $0.24 \pm 0.09,0.039 \pm 0.01$ and $0.029 \pm 0.01$, respectively, indicating the decreasing of the sulphur surface coverage with the cycling. In the beginning of the test while supplying of $1 \mathrm{ppm} \mathrm{H}_{2} \mathrm{~S}$ gas the surface of platinum has been partially covered with the adsorbed sulphur and has not reached $1(100 \%)$ apparently because of the low concentration of $\mathrm{H}_{2} \mathrm{~S}$ species. By the last cycle more than $88 \%$ of the adsorbed species 
have been removed from the surface. The adsorption/desorption of sulphur may lead to the geometric reconstruction of platinum surface that may effect on the ECSA losses. Furthermore, the performed AST is accompanied by a decrease of adsorbed species on platinum due to the partial reversibility of the chemisorption process by oxidation at potentials above $0.95 \mathrm{~V}$ vs RHE (15).

As it was reported by Sun the dissociative adsorption of sulphur on platinum may lead to the geometric arrangement of these atoms on Pt surface (15). The formation of a chemical bond between platinum surface layer and sulphur adsorbed molecule modify the local embedding charge density of platinum reconstructing into lower density arrangements to reduce the local charge density (16). Similar assumption was done by Garsany, when the impact of $\mathrm{SO}_{2}$ on $\mathrm{Pt}_{3} \mathrm{Co}$ and $\mathrm{Pt} / \mathrm{Vulcan}$ was studied by $\mathrm{RDE}$ experiments in $0.1 \mathrm{M} \mathrm{HClO}_{4}$. It was determined that the loss of mass activity of platinum poisoned by adsorbed sulphur can be associated to the deactivation of the platinum sites that relocates the interstitial sites between atoms or modifies the electronic states of the neighbouring Pt atoms (11).

To evaluate the electrocatalytic activities of the $\mathrm{H}_{2} \mathrm{~S}$-poisoned catalyst the ORR measurements were performed. Figure 4 presents ORR curves before and after AST for the reference and $\mathrm{H}_{2} \mathrm{~S}$-poisoned catalysts. It shows that the starting potential is equal to $1.14 \mathrm{~V}$ for all samples. Before AST for reference and poisoned catalyst the ORR is under diffusion-kinetic control in the range between 0.67 and $0.97 \mathrm{~V}$ while at $0.82 \mathrm{~V}$ is under diffusion control. The limiting diffusion current of $2740 \mu \mathrm{A} \mathrm{cm} \mathrm{cm}^{-2}$ for the reference sample before test is reached at $0.62 \mathrm{~V}$ while after AST the limiting current plateau with the value of $2690 \mu \mathrm{A} \mathrm{cm}^{-2}$ starts at around $0.54 \mathrm{~V}$ indicating higher diffusion limitation after AST. For the $\mathrm{H}_{2} \mathrm{~S}$-poisoned sample before AST the ORR is under diffusion control at $0.54 \mathrm{~V}$ while after test the diffusion limiting current is reached at $0.66 \mathrm{~V}$ with an average value of $2820 \mu \mathrm{A} \mathrm{cm}^{-2}$ in both cases.

a)

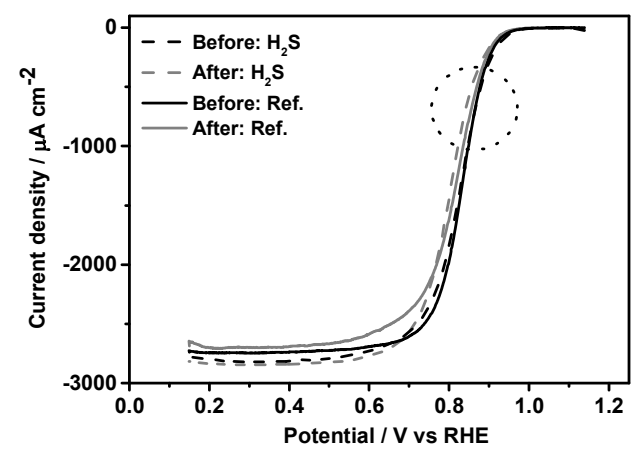

b)

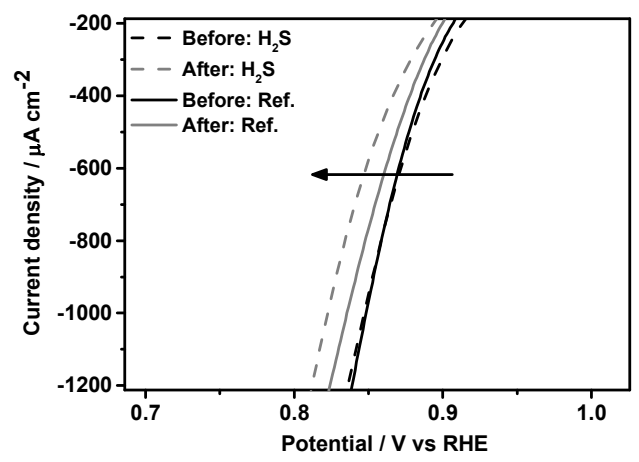

Figure 4. (a) ORR curves of platinum in $\mathrm{O}_{2}$-saturated $0.1 \mathrm{M} \mathrm{HClO}_{4}$ at scan rate $10 \mathrm{mV} \mathrm{s}^{-1}$ by $400 \mathrm{rpm}$ before and after AST for reference and $\mathrm{H}_{2} \mathrm{~S}$-poisoned catalyst and (b) enlargement of the mixed kinetic diffusion region. 
The oxygen reduction reaction is negatively shifted to lower potentials after the AST for both samples and in the presence of $\mathrm{H}_{2} \mathrm{~S}$ the shift is more pronounced confirming stronger decrease of activity in the presence of contaminations.

Similar observation was reported by Garsany et al. where it was shown that adsorbed sulphur species on carbon-supported Pt nanoparticles substantially hinders the oxygen reduction reaction (ORR). The inhomogeneous loss of activity was attributed to the sulphur coverage while each adsorbed sulphur species blocks multiple platinum sites, by locating in the intermediate sites between atoms (17). Baturina et al. was studied the products of the $\mathrm{SO}_{2}$ adsorption on commercial Pt-based catalyst at different electrode potentials by X-ray absorption near-edge structure. The adsorbed sulphur atoms as the products of $\mathrm{SO}_{2}$ reduction at $0.1-0.7 \mathrm{~V}$ were detected confirming platinum-sulphur electronic interactions (18).

At a potential of around $0.85 \mathrm{~V}$ vs RHE the total current $(j)$ depends on limitation of ORR kinetics and oxygen diffusion. The kinetic current could be obtained using the Koutecky-Levich Eq. [5]:

$$
\frac{1}{j}=\frac{1}{j_{\text {kin }}}+\frac{1}{j_{\text {lim }}}
$$

where $j$ is current density at $0.85 \mathrm{~V}, j_{\text {kin }}$ is current density limited by kinetics, $j_{\text {lim }}$ is diffusion-limited current density (8).

The mass and specific activities for reference and $\mathrm{H}_{2} \mathrm{~S}$-poisoned electrodes were calculated from the kinetic limiting current at $0.85 \mathrm{~V}$ and results are shown in Table II. The reference sample before AST has a mass and specific activity of $38.61 \mathrm{~mA} \mathrm{mg}^{-1}$ and $0.066 \mathrm{~mA} \mathrm{~cm}^{-2}$, respectively, compared to $36.45 \mathrm{~mA} \mathrm{mg}^{-1}$ and $0.06 \mathrm{~mA} \mathrm{~cm}^{-2}$ for poisoned catalyst. After AST there is $28 \%$ loss of mass activity to $27.67 \mathrm{~mA} \mathrm{mg}^{-1}$ for reference catalyst and $50 \%$ loss to $18.18 \mathrm{~mA} \mathrm{mg}^{-1}$ for $\mathrm{H}_{2} \mathrm{~S}$-poisoned sample. The specific activity of the reference sample dropped to $0.064 \mathrm{~mA} \mathrm{~cm}{ }^{-2}$ while for the poisoned one it decreased to $0.042 \mathrm{~mA} \mathrm{~cm}^{-2}$ indicating 3 and $30 \%$ losses, respectively. As it was mentioned previously the high loss of activity for the $\mathrm{H}_{2} \mathrm{~S}$-poisoned sample may be related to the adsorbed sulphur species which deactivate multiple platinum sites by rearranging the interstitial sites between platinum atoms or modify the electronic states of the Pt surrounding atoms.

TABLE II. Comparison of the Electrochemical Properties of Platinum Catalyst Before and After AST in the Absent and Presence of $\mathrm{H}_{2} \mathrm{~S}$.

\begin{tabular}{|c|c|c|c|c|c|c|}
\hline \multirow[t]{2}{*}{ Parameter } & \multicolumn{3}{|c|}{ Reference Sample } & \multicolumn{3}{|c|}{$\mathrm{H}_{2} \mathrm{~S}$-Poisoned Sample } \\
\hline & Before & After & Loss, \% & Before & After & Loss, $\%$ \\
\hline Kinetic limiting current, $\mathrm{mA}$ & 0.151 & 0.108 & 28 & 0.143 & 0.071 & 50 \\
\hline Mass activity, $\mathrm{mA} \mathrm{mg}^{-1}$ & 38.61 & 27.67 & 28 & 36.45 & 18.18 & 50 \\
\hline Specific activity, $\mathrm{mA} \mathrm{cm}{ }^{-2}$ & 0.066 & 0.064 & 3 & 0.060 & 0.042 & 30 \\
\hline Tafel slope $(>0.85 \mathrm{~V}), \mathrm{mV} \mathrm{dec}^{-1}$ & 61 & 67 & - & 62 & 57 & - \\
\hline Tafel slope $(<0.85 \mathrm{~V}), \mathrm{mV} \mathrm{dec}{ }^{-1}$ & 120 & 124 & - & 119 & 125 & - \\
\hline
\end{tabular}


Tafel slopes for platinum catalyst during ORR were determined from the plot of E vs $\log j_{k i n}$ and are listed in Table II for comparison including two distinct regions, one at low overpotentials $(>0.85 \mathrm{~V})$, and the other at high overpotential $(<0.85 \mathrm{~V})(19)$. The Tafel slopes for all the samples in the low $(>0.85 \mathrm{~V})$ and high $(<0.85 \mathrm{~V})$ overpotential regions are very close to the expected value of $60 \mathrm{mV} \mathrm{dec}^{-1}$ and $120 \mathrm{mV} \mathrm{dec}^{-1}$, respectively, that is typical for oxygen reduction mechanism on platinum electrodes involving the first order electron transfer as the rate determining step (10).

Further investigation of the impact of the contamination on platinum catalyst was done by HR-TEM in order to give microscopic insights into the catalyst changes. Figure 5 presents HR-TEM images, EDX mapping and particle size distribution of the $\mathrm{H}_{2} \mathrm{~S}$ poisoned platinum catalyst before and after AST.
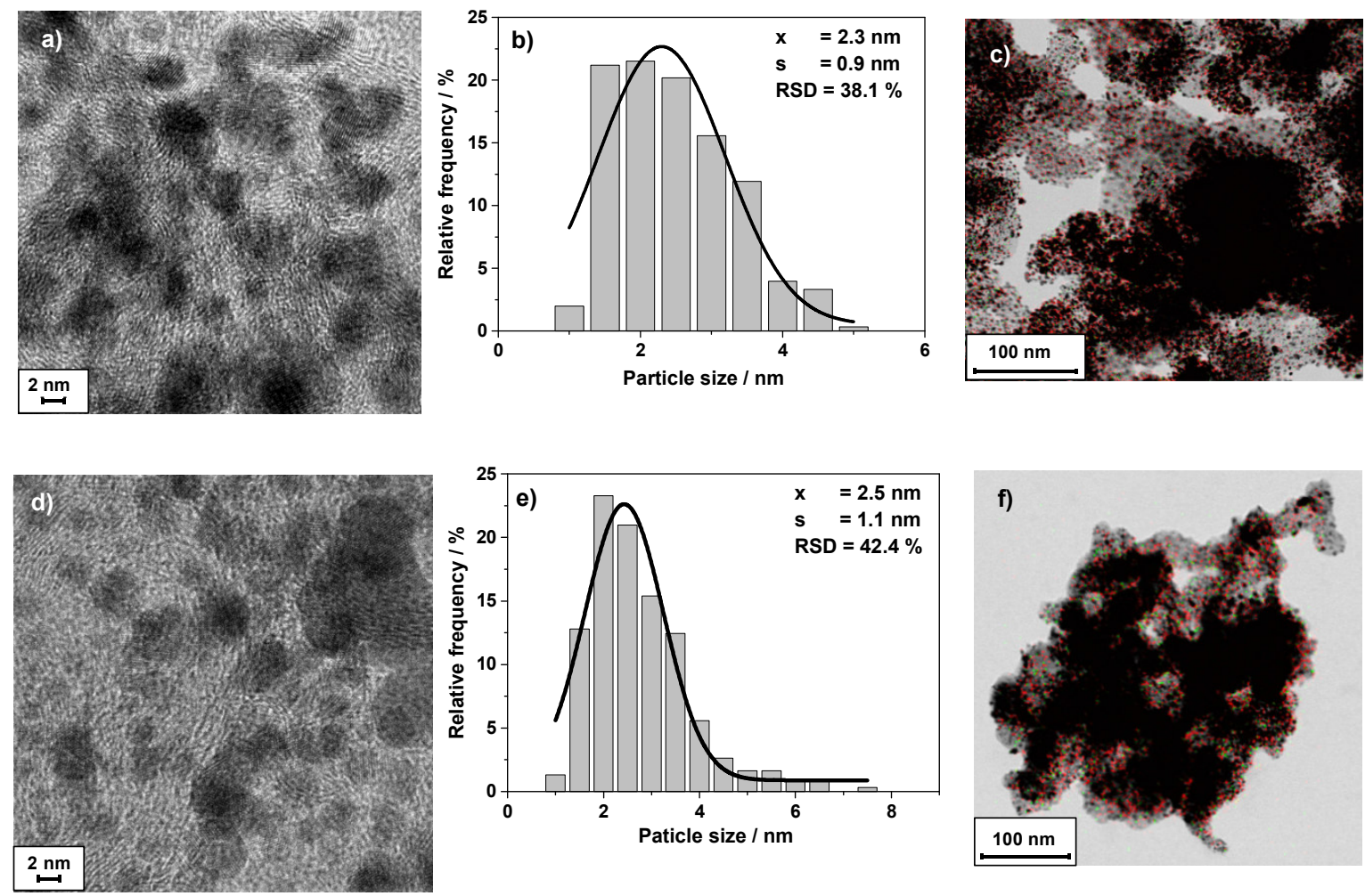

Figure 5. HR-TEM images (a), (d); particle size distribution of the platinum catalyst (b), (e); EDX mapping with elemental distribution of platinum (red dots) and sulphur (green dots) (c), (f) before (a, b, c) and after (d, e, f) AST.

It was determined that there are no significant changes of the catalyst after test: dissolution, detachment or agglomeration of platinum particles was not observed. The particle size of the catalyst slightly changes from $2.3 \mathrm{~nm}$ to $2.5 \mathrm{~nm}$ indicating that influence of sulphur adsorption can be destinguished only at atomic scale.

By EDX mapping the good distribution of Pt particles was observed before as well as after test. Both samples contain sulphur due to the presence of perfluorosulfonic acid- 
based ionomer. However, after AST the amount of sulphur is significantly increased from $8.5 \%$ to $39.4 \%$ confirming that sulphur has adsorbed on the platinum catalyst surface during AST.

\section{Conclusion}

In this work the effect of $\mathrm{H}_{2} \mathrm{~S}$ contaminations on platinum catalyst in PEMFC has been investigated in terms of $\mathrm{RDE}$ measurements in $0.1 \mathrm{M} \mathrm{HClO}_{4}$. Based on cyclic voltammetry of HUPD and CO stripping method it was determined that after AST the losses of ECSA of the catalyst are significantly higher in the presence of $\mathrm{H}_{2} \mathrm{~S}$ in comparison to the reference sample tested without contaminations. The fact was related to the presence of the adsorbed sulphur on the catalyst surface that changed cyclic voltammetric characteristics of the material. The RDE experiments revealed that ORR mass and specific activities were essentially decreased after AST with $\mathrm{H}_{2} \mathrm{~S}$ contaminations attributed to the interstitial defect on platinum atom sites due to the adsorbed sulphur. The results of this study are in a good agreement with previously reported observations about the impact of the sulphur chemisorption on platinum catalyst.

The calculation of the sulphur surface coverages demonstrated the decrease of the coverage with AST cycling indicating partial reversibility of the sulphur adsorption process.

The HR-TEM has not revealed significant difference between the catalyst surface morphology before and after test while the particle size was slightly changed from $2.3 \mathrm{~nm}$ to $2.5 \mathrm{~nm}$. However, EDX mapping showed that after AST the amount of the sulphur is increased suggesting the presence of the adsorbed sulphur species on the catalyst surface.

\section{Acknowledgment}

The authors thank the German Ministry of Economics and Energy for financial support in the framework of the project HAlMa under grant No. 03Et6098D.

\section{References}

1. T.S. Olson, B. Blizanac, B. Piela, J. R. Davey, P. Zelenay, and P. Atanassov, Fuel Cells, 09, 547 (2009).

2. C. Takei, K. Kakinuma, K. Kawashima, K. Tashiro, M. Watanabe, and M. Uchida, J. Power Sources, 324, 729 (2016).

3. S. Shrestha, S. Ashegi, J. Timbro, C. M. Lang, and W. E. Mustain, ECS Trans., 41 (1), 1183 (2011).

4. M. Shao, Q. Chang, J. Dodelet and R. Chenitz, Chem. Rev., 116, 3594 (2016).

5. H. Li, S. Knights, Z. Shi, J. Zee, and J. Zhang, Green Chemistry and Chemical Engineering, p. 210, Taylor and Francis Group (1964).

6. T. Loucka, J. Electroanal. Chem., 31, 319 (1971).

7. V. A. Sethuraman and J. Weidner, Electrochim. Acta, 55, 5683 (2010). 
8. R. Mothadi, W. Lee, S. Cowan, J. W. Van Zee and M. Murthy, Electrochem. Solid-State Lett., 6, A272 (2003).

9. R. Mohtadi, W. Lee, and J. W. Van Zee, Appl. Catal. B, 56, 37 (2004).

10. Y. Nagahara, S. Sugawara, and K. Shinohara, J. Power Sources, 182, 422 (2008).

11. Y. Garsany, O. Baturina, and K. Swider-Lyons, ECS Trans., 11 (1), 863 (2007).

12. D. Schonvogel, J. Hülstede, P. Wagner, A. Dyck, C. Agert, and M. Wark, ECS Trans., 80 (8),879 (2017).

13. T. Nagai, H. Murata, and Y. Morimoto, J. Electrochem. Soc., 161, F789 (2014).

14. X P. Urchaga, S. Baranton, C. Coutanceau, and G. Jerkiewicz, Langmuir, 28, 3658 (2012).

15. S. Sun, S. Chen, N. Li, G. Lu, B. Chen, and F. Xu, Colloids Surf., 134, 207 (1998)

16. S. Titmuss, A. Wander, and D. A. King, Chem Rev., 96, 1291 (1996).

17. Y. Garsany, O. A. Baturina, and K. E. Swider-Lyons, J. Electrochem. Soc., 154 B670 (2007).

18. O. A. Baturina, B. D. Gould, A. Korovina, Y. Garsany, R. Stroman, and P.A. Northhrup, Langmur, 27, 14930 (2011).

19. C. Song and J. Zhang, Electrocatalytic Oxygen Reduction Reaction, Springer (2008). 